\title{
COMPARAÇÃO ENTRE EXAMES DE IMAGEM E ACHADOS OPERATÓRIOS EM DOADORES PARA TRANSPLANTE HEPÁTICO INTERVIVOS
}

\author{
Alexandre Coutinho Teixeira de FREITAS, José Luiz de GODOY, Jorge E. Fouto MATIAS, \\ Lucinei Geraldo STADNIK e Júlio Cezar Uili COELHO
}

\begin{abstract}
RESUMO - Racional - No transplante hepático intervivos a anatomia da tríade portal e da drenagem venosa hepática do doador são de suma importância para o sucesso do procedimento. Objetivo - Analisar comparativamente os achados de exames de imagem no pré-operatório com os achados cirúrgicos em relação à anatomia da tríade portal e veias de drenagem hepática em doadores para transplante hepático intervivos. Métodos - No período de março de 1998 a agosto de 2005 foram revisados os prontuários dos doadores para transplante hepático intervivos realizados no Hospital de Clínicas da Universidade Federal do Paraná, Curitiba, PR. A anatomia no pré-operatório foi analisada através de: a) arteriografia celíaca e mesentérica para a artéria hepática e veia porta (fase venosa); b) ressonância magnética para a drenagem venosa, veia porta e vias biliares. Critérios de normalidade foram estabelecidos de acordo com estudos da literatura. Os achados pré-operatórios foram comparados com os achados peroperatórios no doador. Resultado - Em relação à anatomia da veia porta e artéria hepática foram estudados 44 pacientes, 16 do sexo feminino e 28 do sexo masculino, com idade média de 33 anos. Em 8 casos foi captado o lobo hepático esquerdo para receptor pediátrico e em 36 casos o lobo hepático direito para receptor adulto. Em relação à anatomia biliar foram estudados 37 casos e em relação à anatomia da drenagem venosa, 32 casos. No total, em $36,36 \%$ dos casos, os achados referentes à anatomia nos exames pré-operatórios não coincidiram com os achados peroperatórios. Para a artéria hepática os achados foram discordantes em $11,36 \%$ dos casos, para a veia porta foram discordantes em $9,1 \%$, para a drenagem venosa em $9,37 \%$ e para as vias biliares em 21,6\%. Conclusão - São freqüentes achados discrepantes referentes à anatomia da tríade portal e drenagem venosa hepática na análise pré-operatória do doador para transplante hepático intervivos em relação aos achados peroperatórios.

DESCRITORES - Fígado, anatomia \& histologia. Ductos biliares, anatomia \& histologia. Fígado, cirurgia. Transplante de fígado. Veia porta. Artéria hepática.
\end{abstract}

\section{INTRODUÇÃO}

Variações anatômicas da tríade portal e da drenagem venosa hepática são freqüentes e de suma importância para o transplante hepático, devido à necessidade de utilização de estratégias alternativas para as anastomoses. A correta identificação da anatomia no pré-operatório evita que o cirurgião encontre situações inesperadas, de difícil correção e que, em alguns casos, até impeçam a realização do transplante.

O transplante hepático intervivos é modalidade relativamente recente na prática cirúrgica, introduzido por RAIA et al. em $1989^{(19)}$. Trata-se de procedimento mais desafiador do ponto de vista técnico, com necessidade ainda mais importante de definição da anatomia no préoperatório $^{(8)}$. A bipartição do fígado do doador é cirurgia complexa que aborda os três elementos do hilo hepático - artéria hepática, veia porta e ducto hepático - e também o sistema de drenagem venosa - veias supra-hepáticas direita, média e esquerda e ramos retrohepáticos diretos do parênquima para a veia cava inferior retrohepática dependendo do caso.

No pré-operatório do transplante hepático intervivos diversas modalidades de exames de imagem são utilizadas para análise do doador. A arteriografia celíaca e mesentérica determina a anatomia da artéria hepática e sua fase venosa a anatomia da veia porta; a ressonância nuclear magnética determina a anatomia biliar, portal e do sistema venoso de drenagem, podendo realizar ainda a medida volumétrica dos lobos hepáticos. Outros métodos também podem ser utilizados, como: angiotomografia, colangiografia endoscópica e esplenoportografia.

Apesar de adequada análise pré-operatória, normalmente utilizando-se exames de tecnologia avançada e alto custo, em muitas situações os achados cirúrgicos são diferentes e a estratégia cirúrgica é modificada.

O objetivo deste estudo foi determinar as mais freqüentes variações anatômicas da tríade portal e do sistema de

Serviço de Transplante Hepático do Hospital de Clínicas da Universidade Federal do Paraná, Curitiba, PR.

Correspondência: Dr. Alexandre C. Teixeira de Freitas - Rua Brasílio Itiberê, 4029 - apt. 52.80240-060 - Curitiba, PR. E-mail: alexandrefreitas@ufpr.br 
drenagem hepática observadas em doadores do transplante hepático intervivos e correlacionar os achados pré-operatórios com os achados cirúrgicos.

\section{MÉTODO}

No período de março de 1998 a agosto de 2005 foram revisados os prontuários dos doadores de lobo hepático para transplante intervivos realizados no Hospital de Clínicas da Universidade Federal do Paraná, Curitiba, PR.

Foram computados os laudos dos exames de imagem realizados no protocolo pré-operatório. Foram excluídos do estudo pacientes sem a descrição dos laudos dos exames de imagem. De interesse para o estudo foram verificados: a) arteriografia do tronco celíaco e artéria mesentérica superior, inclusive com análise da fase venosa; b) ressonância nuclear magnética de abdome com reconstrução da drenagem venosa hepática, anatomia portal e biliar. $\mathrm{Na}$ arteriografia foram analisadas as possíveis variações anatômicas da artéria hepática, tronco celíaco e artéria mesentérica superior. Em sua fase venosa, a descrição da anatomia da veia porta, principalmente no mesmo plano de sua bifurcação e ramificação intra-hepática. $\mathrm{Na}$ ressonância nuclear magnética de abdome foi analisada a distribuição das veias supra-hepáticas e verificação da existência de veias anômalas retrohepáticas com drenagem direta para a veia cava inferior. Ainda, a bifurcação da veia porta e suas ramificações intra-hepáticas e anatomia das vias biliares. Na análise da anatomia da veia porta considerou-se o laudo da fase venosa da arteriografia e/ou o laudo da ressonância nuclear magnética.

Os achados operatórios foram coletados das descrições cirúrgicas. Esses achados foram utilizados como referência para cruzamento com os achados dos exames de imagem. Em relação à drenagem venosa hepática, nos casos de doação de lobo hepático direito, as veias supra-hepáticas média e esquerda não são dissecadas, não sendo possível a determinação de sua anatomia. A análise das veias supra-hepáticas foi excluída da comparação com os achados de exames de imagem. Logo, em relação à drenagem venosa hepática: a) a anatomia das veias supra-hepáticas e das veias anômalas retrohepáticas com drenagem direta para a veia cava inferior foi descrita de acordo com os achados da ressonância magnética; não foram descritos achados cirúrgicos porque a veia hepática média e esquerda não são dissecadas na captação do lobo hepático direito; b) foi analisada a presença de veias com calibre superior a $0,5 \mathrm{~cm}$, drenando o setor anterior direito (segmentos $\mathrm{Ve}$ VIII) para a veia hepática média durante a cirurgia de captação do lobo direito; esses dados não foram comparados com os achados de exame de imagem por não serem analisados no pré-operatório; c) os achados cirúrgicos foram analisados comparativamente com os de exame de imagem somente em relação à presença de veias variantes retrohepáticas com drenagem direta para a veia cava inferior (para análise dessas veias, foram excluídos os casos de doação de lobo hepático esquerdo, visto que a veia cava inferior retrohepática não é dissecada nessa situação).

A anatomia da artéria hepática foi considerada normal quando a artéria hepática comum originou-se no tronco celíaco, após a emergência da artéria gastroduodenal, denominando-se artéria hepática própria, bifurcando-se em artéria hepática direita e artéria hepática esquerda na altura do hilo hepático, conforme a Figura $1 \mathrm{~A}^{(16,23)}$. A veia porta foi considerada normal quando formada pela união da veia mesentérica superior e veia esplênica, ramificando-se à altura do hilo hepático em ramo direito e ramo esquerdo da veia porta, conforme a Figura $2 \mathrm{~A}$. O ramo direito, dividindo-se em ramo direito anterior e ramo direito posterior, $\mathrm{e}$ o ramo esquerdo, dividindo-se em ramo esquerdo anterior e ramo esquerdo posterior, foram considerados como anatomia normal da ramificação intra-hepática ${ }^{(23)}$. Considerou-se anatomia normal da drenagem venosa hepática a desembocadura da veia supra-hepática direita na veia cava inferior e a união das veias supra-hepáticas média e esquerda em tronco único antes de sua drenagem para a veia cava inferior. Veias de drenagem direta do fígado para veia cava inferior retrohepática com menos que $0,5 \mathrm{~cm}$ de diâmetro foram consideradas normais. Considerou-se anatomia normal das vias biliares extra-hepáticas a formação do ducto hepático comum a partir da união dos ductos hepáticos direito e esquerdo no hilo hepático, denominando-se ducto colédoco após a emergência do ducto cístico, conforme a Figura $3 \mathrm{~A}^{(23)}$.

As variações da artéria hepática foram descritas de acordo com o estudo de MICHELS ${ }^{(16)}$, representado na Tabela 1. A Figura 1B

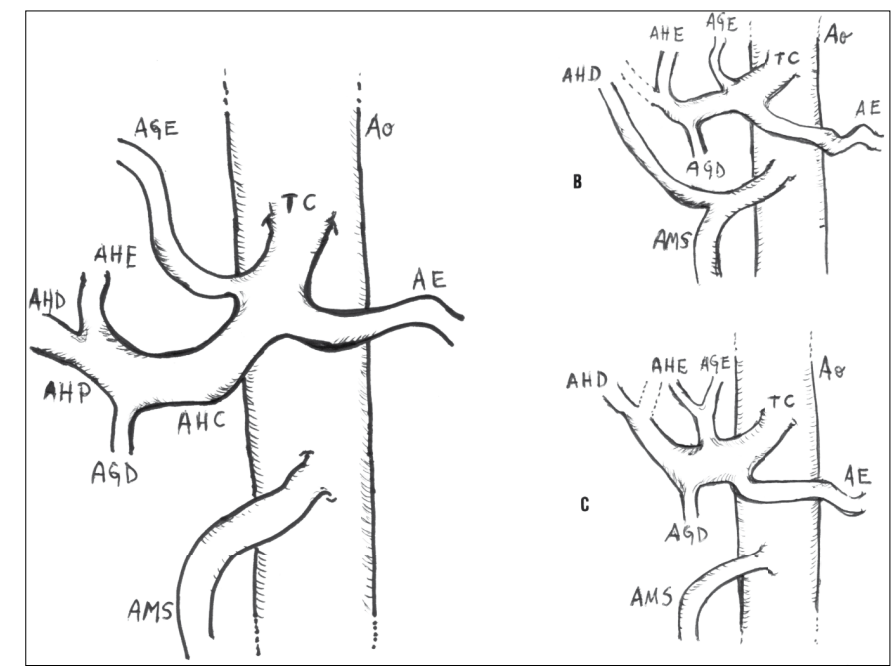

FIGURA 1. Anatomia normal da artéria hepática e principais variações anatômicas. A - anatomia normal da artéria hepática; B - representação da artéria hepática direita ramo da artéria mesentérica superior; $\mathrm{C}$ - representação da artéria hepática esquerda ramo da artéria gástrica esquerda. Nos casos de artéria hepática direita acessória e artéria hepática esquerda acessória, o tronco original, representado em linhas pontilhadas, está presente

AO - aorta; TC - tronco celíaco; AHC - artéria hepática comum; AGD - artéria gastroduodenal; AHP - artéria hepática própria; AHD - artéria hepática direita; AGE - artéria gástrica esquerda; AE - artéria esplênica; AGE - artéria gástrica esquerda; AMS - artéria mesentérica superior

demonstra a artéria hepática direita, ramo da artéria mesentérica superior, e a Figura $1 \mathrm{C}$ a artéria hepática esquerda, ramo da artéria gastrica esquerda. As variações da veia porta foram classificadas em quatro tipos, de acordo com o estudo de CHENG et al. ${ }^{(3)}$. No tipo I ocorre o padrão normal, com bifurcação do tronco principal da veia porta em ramo direito e ramo esquerdo. No tipo II há trifurcação 
da veia porta em ramo direito posterior, ramo direito anterior e ramo esquerdo (Figura 2B). No tipo III o tronco principal da veia porta fornece, inicialmente, o ramo direito posterior seguido do ramo direito anterior e finalmente o ramo esquerdo (Figura $2 \mathrm{C}$ ). No tipo IV o ramo direito anterior tem origem na veia porta esquerda. Variações da drenagem venosa hepática foram classificadas de acordo com NAKAMURA e TSUZUKI ${ }^{(17)}$ : a) anatomia normal; b) veia supra-hepática esquerda e média com implante separado na veia cava inferior; c) veia retrohepática com drenagem direta do parênquima para a veia cava inferior com calibre superior a $0,5 \mathrm{~cm}$. As variações biliares foram descritas de acordo com COUINAUD $^{(5)}$. Nesse estudo as vias biliares foram classificadas em: a) anatomia normal; b) trifurcação da via biliar (Figura 3B); c) ducto setorial anterior ou posterior direito, unindo-se ao ducto hepático esquerdo (Figura 3C); d) ducto setorial anterior ou posterior direito, unindo-se ao ducto hepático comum; e) ausência de ductos hepáticos direito ou esquerdo; f) ducto setorial posterior direito implantando-se no ducto cístico.

TABELA 1. Anatomia da artéria hepática de acordo com Michels

\begin{tabular}{llc}
\hline Tipo & Descrição & $\%$ \\
\hline I & Normal & 55 \\
II & AHE ramo AGE & 10 \\
III & AHD ramo AMS & 11 \\
IV & AHD ramo AMS, AHE ramo AGE & 1 \\
V & AHE acessória ramo AGE & 8 \\
VI & AHD acessória ramo AMS & 7 \\
VII & AHD acessória ramo AMS, AHE acesssória ramo AGE & 1 \\
VIII & AHD ramo AMS, AHE acessória ramo AGE ou & 2 \\
IX & AHE ramo AGE, AHD acessória ramo AMS & \\
X & AHC ramo AMS & 2,5 \\
\hline
\end{tabular}

AHE - artéria hepática esquerda; $A G E$ - artéria gástrica esquerda; $A H D$ - artéria hepática direita; $A M S$ - artéria mesentérica superior; $A H C$ - artéria hepática comum

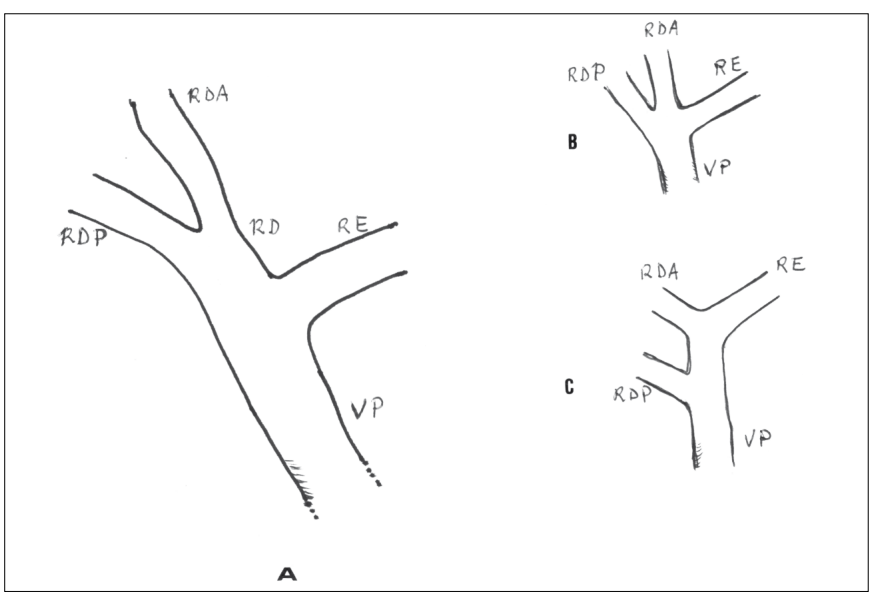

FIGURA 2. Anatomia normal da veia porta e principais variações anatômicas. A - anatomia normal da veia porta; B - trifurcação da veia porta (Cheng tipo II); $\mathrm{C}$ - ramificação precoce do ramo direito posterior para o lobo direito (Cheng tipo III)

VP - veia porta; RE - ramo esquerdo da veia porta; RD - ramo direito da veia porta; RDP - ramo direito posterior; RDA - ramo direito anterior

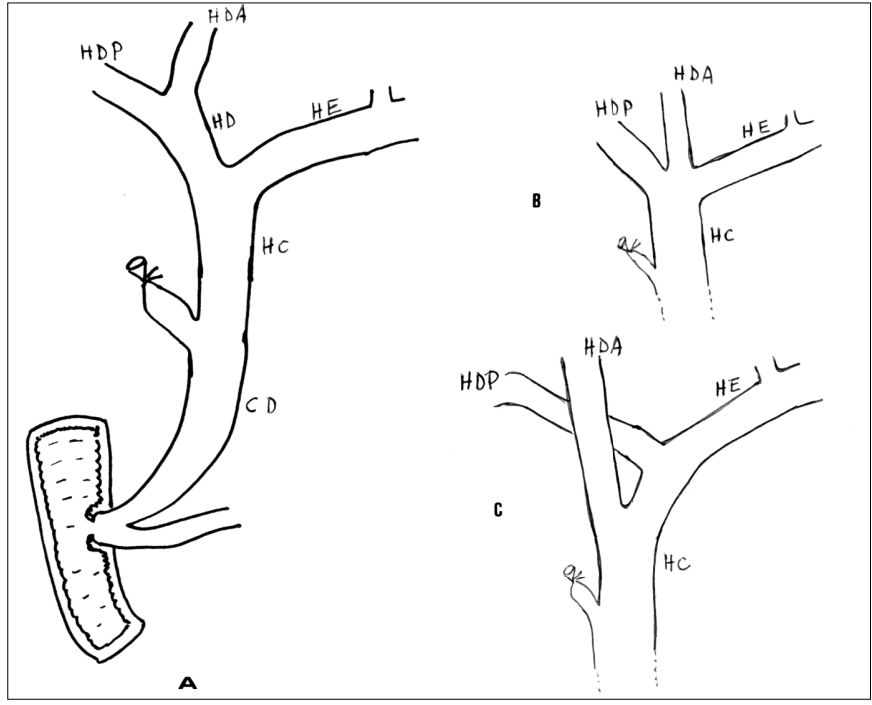

FIGURA 3. Anatomia normal das vias biliares e principais variações anatômicas. A - anatomia normal das vias biliares; B - trifurcação da via biliar; $\mathrm{C}$ - ducto hepático direito posterior unindo-se ao ducto hepático esquerdo CD - colédoco; HC - ducto hepático comum; HE - ducto hepático esquerdo; HD - ducto hepático direito; HDP - ducto hepático direito posterior; HDA - ducto hepático direito anterior

\section{RESULTADO}

Inicialmente foram analisados 51 pacientes, 7 foram excluídos devido a dados insuficientes no prontuário. Foram incluídos 44 pacientes, 16 do sexo feminino e 28 do sexo masculino, com idade média de 33 anos. Em 8 casos foi captado o lobo hepático esquerdo para receptor pediátrico e em 36 casos o lobo hepático direito para receptor adulto.

Todos os 44 doadores realizaram arteriografia com fase venosa no pré-operatório e foram incluídos para análise da anatomia arterial e portal. Em sete casos, três doadores de lobo esquerdo e quatro de lobo direito, o resultado da ressonância nuclear magnética não foi localizado no prontuário. Esses pacientes foram excluídos da análise da anatomia biliar, restando 37 casos. Em relação à análise das veias retrohepáticas variantes com drenagem direta do parênquima para a veia cava inferior, foram excluídos os sete casos em que o resultado da ressonância magnética não foi localizado no prontuário e também os cinco doadores de lobo esquerdo restantes. Logo, 32 pacientes foram incluídos na análise das veias retrohepáticas variantes.

Considerando-se a análise geral dos dados, em 16 casos (36,3\%) os achados referentes à anatomia nos exames pré-operatórios não coincidiram com os achados do peroperatório.

A anatomia da artéria hepática pela arteriografia e pela análise operatória foi normal em 33 casos. Em todos eles o achado da arteriografia foi coincidente com o da cirurgia. Variações anatômicas arteriais foram observadas em 11 pacientes $(25 \%)$, tanto no exame de imagem quanto na cirurgia. Destes, em seis casos os achados da arteriografia foram coincidentes com o achado peroperatório. Estes casos, somados aos 33 com anatomia normal, correspondem a $88,6 \%$ de achados coincidentes entre a 
arteriografia e a cirurgia (Tabela 2$)$. Em cinco casos $(11,4 \%)$, os achados referentes à anatomia na arteriografia não coincidiram com os achados peroperatórios (Tabela 3).

TABELA 2. Anatomia coincidente da artéria hepática na arteriografia e na cirurgia

\begin{tabular}{lcc}
\hline Anatomia da artéria hepática & $\mathbf{n}$ & $\%$ \\
\hline Normal & 33 & 75 \\
AHD ramo da AMS & 3 & 6,7 \\
AHD acessória ramo AMS & 1 & 2,3 \\
2 AHE ramos da AHC & 1 & 2,3 \\
AHD ramo do TC, AHE ramo da AHC & 1 & 2,3 \\
Total & 39 & 88,6 \\
\hline
\end{tabular}

AHD - artéria hepática direita; AMS - artéria mesentérica superior; AHE - artéria hepática esquerda; $A H C$ - artéri hepática comum; TC - tronco celíaco

TABELA 3. Anatomia discrepante da artéria hepática na arteriografia e na cirurgia

\begin{tabular}{llcc}
\hline Arteriografia & Cirurgia & $\mathbf{n}$ & $\%$ \\
\hline Artérias hepáticas ramo do TC & AHD ramo da AG & 1 & 2,3 \\
Artérias hepáticas ramo do TC & Normal & 2 & 4,5 \\
$\begin{array}{l}\text { AHD ramo da AMS, AHE ramo } \\
\text { do TC }\end{array}$ & $\begin{array}{l}\text { AHD ramo da AMS, AHE ramo } \\
\text { da AGE }\end{array}$ & 1 & 2,3 \\
AHD ramo da AMS & $\begin{array}{l}\text { AHD ramo da AMS, AHE ramo } \\
\text { da AGE }\end{array}$ & 1 & 2,3
\end{tabular}

Total

$5 \quad 11,4$

AHD - artéria hepática direita; AMS - artéria mesentérica superior; AHE - artéria hepática esquerda; TC - tronco celíaco; $\mathrm{AG}$ - artéria gastroduodenal; $\mathrm{AGE}$ - artéria gástrica esquerda

Anatomia normal da veia porta foi observada em 40 casos $(90,9 \%)$. Em quatro casos $(9,1 \%)$ foram observadas variações anatômicas. A anatomia da veia porta, através da análise da fase venosa da arteriografia e/ou ressonância nuclear magnética, foi igual ao achado peroperatório em 40 casos (90,9\%), todos com anatomia normal. Nos quatro casos com variações anatômicas, os achados dos exames de imagem pré-operatórios foram discordantes com os da cirurgia (Tabela 4).

TABELA 4. Anatomia discrepante da veia porta na fase venosa da arteriografia, na ressonância nuclear magnética e na cirurgia

\begin{tabular}{lllcc}
\hline Fase venosa & RNM & Cirurgia & $\mathbf{n}$ & $\%$ \\
\hline Normal & Normal & Tipo II de Cheng & 2 & 4,5 \\
Normal & Normal & Tipo III de Cheng & 1 & 2,3 \\
Não realizada & TipoIII (Cheng) & $\begin{array}{l}\text { Ramo portal do lobo esquerdo com } \\
\text { desembocadura na VPD, presença de VPE }\end{array}$ & 1 & 2,3 \\
& & em sua posição habitual & & \\
Total & & & 4 & 9,1 \\
\hline
\end{tabular}

RNM - ressonância nuclear magnética; VPD - veia porta direita; VPE - veia porta esquerda

Anatomia normal da drenagem venosa hepática foi observada na ressonância magnética em 23 casos (71,9\%). Em nove $(28,1 \%)$ foram observadas variações anatômicas (Tabela 5$)$. Veias retrohepáticas maiores que $5 \mathrm{~mm}$ com drenagem direta para veia cava inferior, foram detectadas em cinco casos (15,6\%). Estes mesmos achados foram observados na cirurgia. Em três casos $(9,3 \%)$ foram observadas, durante a cirurgia, veias de drenagem do setor anterior direito com mais que $0,5 \mathrm{~cm}$ (segmentos $\mathrm{V}$ e VIII) para a veia hepática média.

Anatomia normal das vias biliares foi observada em 27 casos (73\%). Em 10 (27\%) foram observadas variações anatômicas. A anatomia das vias biliares determinada pela ressonância nuclear magnética foi igual ao achado peroperatório em 29 casos (78,4\%): $26 \mathrm{com}$ anatomia normal e 3 com variações anatômicas (Tabela 6). Em 8 casos $(21,6 \%)$ os achados de imagem pré-operatória foram discordantes com os da cirurgia (Tabela 7).

TABELA 5. Anatomia da drenagem venosa hepática na ressonância nuclear magnética

\begin{tabular}{lcc}
\hline Anatomia da drenagem venosa hepática & $\mathbf{n}$ & $\%$ \\
\hline Normal & 23 & 71,9 \\
Veias supra-hepáticas implantadas separadas na VCI & 4 & 12,5 \\
Veia de drenagem posterior $>5 \mathrm{~mm}$ & 3 & 9,4 \\
Veia de drenagem posterior $>5 \mathrm{~mm}$ e veias supra-hepáticas & 1 & 3,1 \\
implantadas separadas na VCI & & \\
2 veias de drenagem posterior $>5 \mathrm{~mm}$ & 1 & 3,1 \\
Total & 32 & 100 \\
\hline
\end{tabular}

$\mathrm{VCl}$ - veia cava inferior

TABELA 6. Anatomia coincidente das vias biliares na ressonância nuclear magnética e na cirurgia

\begin{tabular}{lcc}
\hline Anatomia das vias biliares & $\mathbf{n}$ & $\%$ \\
\hline Normal & 26 & 70,3 \\
2 ductos para lobo hepático direito & 2 & 5,4 \\
Ducto direito posterior drena para ducto esquerdo & 1 & 2,7 \\
Total & 29 & 78,4 \\
\hline
\end{tabular}

TABELA 7. Anatomia discrepante das vias biliares na ressonância nuclear magnética e na cirurgia

\begin{tabular}{llcc}
\hline RNM & Cirurgia & n & $\%$ \\
\hline Normal & 2 ductos para lobo hepático direito & 6 & 16,2 \\
Normal & 3 ductos para lobo hepático direito & 1 & 2,7 \\
2 ductos para lobo hepático direito & Normal & 1 & 2,7 \\
Total & & 8 & 21,6 \\
\hline
\end{tabular}

\section{DISCUSSÃO}

Variações anatômicas da tríade portal e do sistema de drenagem venosa hepática são descritos em diversos estudos na literatura médica, utilizando-se variados métodos de análise. Nesses estudos observou-se significativa variância em relação aos resultados dependendo do autor e da metodologia utilizada para análise. Essa discrepância de resultados ocorre devido a limitações dos métodos e muito provavelmente do examinador. No nosso meio, devido à existência de relativamente poucos serviços de transplante hepático intervivos, os radiologistas não realizam rotineiramente análise da anatomia de interesse dos transplantadores. Ainda, é necessário interatividade entre a equipe transplantadora e a equipe responsável pela realização dos exames de imagem. Ocorrem situações em que dados anatômicos de interesse não são abordados ou são negligenciados por falta de comunicação entre as equipes.

No transplante hepático intervivos, quando defrontado com um achado anatômico imprevisto, o cirurgião deve ter em mente as possíveis alternativas para obtenção de enxerto apropriado preservando o remanescente do doador.

As variações anatômicas da artéria hepática apresentam freqüência que varia de $23 \%$ a $50 \%{ }^{(1,6,7,10,13)}$. Essas variações podem dificultar o transplante intervivos ${ }^{(8,12)}$. Até há alguns anos, a presença de variações arteriais era contra-indicação ao 
procedimento $^{(2)}$. Nas situações de artéria hepática direita acessória, ramo da artéria mesentérica superior, o lobo hepático direito é vascularizado por dois troncos arteriais, criando a dificuldade de duas reconstruções arteriais no receptor, habitualmente com calibre reduzido. Observou-se esta situação em um caso, reconhecida no pré-operatório através da arteriografia. Nos casos do tronco principal da artéria hepática direita, ramo da artéria mesentérica superior há facilitação do procedimento ${ }^{(18)}$. Nessa situação, além de se realizar somente uma anastomose arterial no receptor, a artéria hepática direita é mais longa devido à possibilidade de secção da mesma em posição mais distal em relação ao fígado. As variações anatômicas da artéria hepática esquerda não interferem com a captação do lobo hepático direito. Observaram-se as mesmas características em relação às variações da artéria hepática esquerda nos casos de transplantes para receptores pediátricos com captação do lobo hepático esquerdo do doador. Neste estudo, nos casos em que se observou discrepância entre os achados préoperatórios e peroperatórios, não houve dificuldade técnica após o reconhecimento da variação anatômica.

Em relação à veia porta, anatomia normal foi observada em $90,9 \%$ dos casos. A reconstrução, no caso de transplante hepático intervivos com doador de lobo hepático direito, foi realizada através da anastomose da veia porta direita do doador no tronco da veia porta do receptor. Variações foram observadas em $9,1 \%$ dos casos, havendo necessidade de técnicas diferentes. Outros autores mostram variações de $10 \%$ a $13,6 \%{ }^{(14,15,24)}$. No caso de variação do tipo II da classificação de Cheng, pode-se utilizar quatro estratégias no processo de hepatectomia parcial para transplante intervivos ${ }^{(14)}$. A primeira opção é a sutura da parede medial da veia anterior com a parede medial da veia posterior, formando um orifício único que é anastomosado no tronco da veia porta do receptor. Outra opção é a utilização de enxerto venoso cadavérico criopreservado da veia ilíaca comum e sua bifurcação em veia ilíaca interna e externa. As veias ilíacas interna e externa são anastomosadas nos dois ramos da veia porta na mesa auxiliar de cirurgia. Utiliza-se a veia ilíaca comum para a anastomose na veia porta do receptor. A terceira opção é a ressecção de segmento da veia porta do receptor, englobando sua bifurcação em ramo portal direito e ramo portal esquerdo. Esses ramos são anastomosados com ramos anterior e posterior do lobo hepático doado na mesa auxiliar de cirurgia. $\mathrm{O}$ tronco da veia porta é usado para a anastomose no remanescente da veia porta no receptor. A quarta opção é a ressecção discóide de parte da parede da veia porta englobando os dois orifícios (anterior e posterior) das veias para o lobo hepático direito. Esse segmento discóide permite a realização de uma única anastomose na veia porta do receptor. $\mathrm{O}$ defeito na veia porta remanescente do doador pode ser ressecado, seguido de anastomose término-terminal ou pode ser submetido a plastia com veia ovariana ou veia jugular.

No tipo III, não se pode realizar a sutura das paredes mediais dos dois vasos para a confecção de tronco único, nem realizar ressecção discóide devido à distância que separa esses dois vasos. Opção que não deve ser considerada é a anastomose direta dos ramos anterior e posterior do doador com os ramos direito e esquerdo da veia porta do receptor. Nessa situação, ocorre desvio do eixo dos vasos com subseqüente torção e grande possibilidade de trombose. Restam as opções de utilização de enxerto venoso criopreservado ou enxerto da veia porta do receptor. O tipo IV não deve ser usado como doador.

Neste estudo, um doador apresentou veia porta do tipo III da classificação de Cheng, não-detectada no pré-operatório. Não foi possível a utilização do enxerto da veia porta do receptor devido à presença de trombose com espessamento da veia e diminuição da sua luz. Não se tinha, também, a disponibilidade de enxerto venoso criopreservado. A trombose da veia porta do receptor também não foi detectada no pré-operatório, apesar de adequada investigação. A única opção restante foi o fechamento da cavidade do doador e do receptor e a não realização do transplante. Os outros casos de discrepância entre os achados pré-operatórios e peroperatórios necessitaram de estratégias alternativas para realização do transplante, porém com sucesso.

As variações da drenagem venosa do fígado têm sua importância nos casos de identificação de veias de drenagem posterior, diretamente para veia cava inferior, com calibre maior ou igual a $0,5 \mathrm{~cm}$ no caso de captação do lobo hepático direito. Essas veias devem ser preservadas e anastomosadas com a veia cava inferior do receptor. A ligadura dessas veias, como realizado habitualmente com veias de calibre inferior a $0,5 \mathrm{~cm}$, está associada ao desenvolvimento de congestão hepática na área drenada por elas, habitualmente os segmentos VI e VII. Neste estudo, todos os cinco casos observados no pré-operatório $(15,6 \%)$ o foram também durante a cirurgia. Excluíram-se da análise os casos de doação de lobo hepático esquerdo porque a veia cava não é dissecada nessa situação. Outros estudos mostram veias de drenagem posterior em $37 \%$ e $61,4 \%$ dos casos, respectivamente ${ }^{(4,17)}$.

A presença de tributárias da veia hepática média com origem no setor anterior direito também deve ser observada. Veias com calibre superior a $0,5 \mathrm{~cm}$ devem ser preservadas e anastomosadas no receptor devido ao risco de congestão nos segmentos V e VIII. Na presente série essa situação foi observada em três casos $(9,37 \%)$. A veia hepática média drena o setor medial esquerdo (segmento IV) e o setor anterior direito (segmentos V e VIII) ${ }^{(17)}$. Nos casos de captação do lobo hepático direito, a drenagem venosa é realizada pela veia hepática direita. Os segmentos V e VIII são drenados por colaterais para a veia hepática direita ${ }^{(14)}$.

Quando se observam veias supra-hepáticas esquerda e média com desembocadura individual na veia cava inferior, não há interferência na captação do lobo direito. Nesta situação esses vasos não são dissecados, motivo pelo qual foram excluídos desta análise. No caso de captação do lobo esquerdo para receptores pediátricos, a presença de veia hepática média com implante separado da veia hepática direita facilita o procedimento, quando se captam somente os segmentos 2 e 3 do lobo esquerdo.

O transplante hepático intervivos apresenta maior incidência de complicações biliares em relação ao cadavérico ${ }^{(8)}$. A presença de variações anatômicas biliares é em parte responsável por esse fato. No transplante hepático cadavérico, a secção da via biliar é realizada no ducto hepático comum ou no ducto colédoco. Nesse ponto, em raras situações são observadas variações. No transplante intervivos são abordados os ductos hepáticos esquerdo e direito, na dependência do lobo hepático doado. O ducto hepático esquerdo é mais longo e menos sujeito a variações. Em $90 \%$ dos casos de doação de lobo hepático esquerdo é obtido orifício único para reconstrução ${ }^{(20)}$. A árvore biliar direita com freqüência 
sofre ramificação precoce. Isso determina a obtenção de mais de um orifício para reconstrução, criando dificuldades técnicas relacionadas ao diâmetro dos mesmos e necessidade de técnicas alternativas para reconstrução biliar no doador. $\mathrm{Na}$ literatura, a obtenção de ducto biliar direito único, no caso de doação do lobo hepático direito, varia de $50 \%$ a $81,08 \%^{(9,11,21,22)}$. A obtenção de dois ductos varia de $12,3 \%$ a $40 \%$ e a obtenção de três ductos varia de $1,2 \%$ a $8 \%{ }^{(9,11,21,22)}$.

Observaram-se nove pacientes com dois ductos para o lobo hepático direito $(24,3 \%)$. Desses, em seis não houve reconhecimento da variação no pré-operatório. Algumas estratégias cirúrgicas, analisadas caso a caso, podem ser usadas no receptor: a) sutura dos dois ductos e confecção de anastomose única no receptor; b) anastomose dos ductos hepáticos direito anterior e posterior do doador com os ductos hepáticos direito e esquerdo do receptor; c) anastomose com alça jejunal em Y-de-Roux no receptor; d) ligadura de um dos ductos, caso apresente diâmetro reduzido, indicando drenagem de área pequena no lobo hepático doado. Em um caso $(2,70 \%)$, obtiveram-se três ductos biliares para o lobo hepático direito. $\mathrm{O}$ exame pré-operatório foi normal.

Conclui-se que achados discrepantes entre a anatomia da veia porta, artéria hepática, vias biliares e drenagem venosa hepática são freqüentes na análise pré-operatória do doador para transplante hepático intervivos, em relação aos achados peroperatórios.

Freitas ACT, Godoy JL, Matias JEF, Stadnik LG, Coelho JCU. Comparison of pre-operative exams and per-operative findings in living donor liver transplantation. Arq Gastroenterol. 2007;44(4):325-31.

ABSTRACT - Background - Success in living donor liver transplantation is associated to donor vascular and biliar anatomy. Aim - Compare pre-operative and per-operative findings in living liver donors related to portal vein, hepatic artery, bile duct and hepatic venous drainage anatomy. Methods - Donors charts of living donor liver transplants done at Clinics Hospital of the Federal University of Paraná, Curitiba, PR, Brazil, were reviewed between March 1998 and August 2005. On the pre-operative period the anatomy was analysed through: celiac and mesenteric arteriography of the hepatic artery and portal vein (venous phase); magnetic resonance imaging of the venous drainage, portal vein and bile duct. Normality was determined based on data of the literature. Pre-operative findings were compared to per-operative findings. Results - Portal vein and hepatic artery were studied in 44 patients, 16 females and 28 males, mean age of 33 years old. In 8 cases the left liver lobe was used to pediatric receptor, in 36 cases the right liver lobe was used to adult receptor. Bile duct anatomy was studied in 37 cases and venous drainage in 32. Over all, the findings related to pre-operative and per-operative anatomy were not coincident in $36.36 \%$ of the cases. In the case of hepatic artery, they were not coincident in $11.36 \%$, in the case of the portal vein in $9.1 \%$, in the case of the venous drainage in $9.37 \%$ and in the case of the bile duct in $21.6 \%$. Conclusion - The pre-operative and per-operative findings related to vascular and bile duct donor anatomy are frequently different in living donor liver transplantation.

HEADINGS - Liver, anatomy \& histology. Bile ducts, anatomy \& histology. Liver, surgery. Liver transplantation. Portal vein. Hepatic artery. 


\section{REFERÊNCIAS}

1. Brems JJ, Millis JM, Hiatt JR. Hepatic artery reconstruction during liver transplantation. Transplantation. 1989;47:403-6.

2. Broelsh CE, Emond JC, Whintington PF, Thistlethwaite JR, Baker AL, Lichtor JL. Application of reduced size liver transplants as split grafts, auxiliary orthotopic grafts, and living related segmental transplants. Ann Surg. 1990;212:368-77.

3. Cheng YF, Huang TL, Lee TY, Chen TY; Chen CL. Variation of the intrahepatic portal vein: angiographic demonstration and application in living-related hepatic transplantation. Transplant Proc. 1996,28:1667-8.

4. Chevalier JM, Delva E, Frileux P, Nordlinger B, Parc R, Huguet C, Hannoun L. L'hepatectomie sous exclusion vasculaire totale. Principes anatomiques d'aprés 64 dissections. Ann Chir. 1990;44:444-51.

5. Couinaud C. Hépatectomie droite, hépatectomie droite étendue ou trisegmentectomie? Considérations sur l'anatomie intra-hépatique et ses applications en chirurgie. Ann Chir. 1979, 33:385-91.

6. Daly JM, Kemeny N, Oderman P. Long term hepatic infusion chemotherapy. Arch Surg. 1984:119:936-41

7. Decurtins JC, Friend JP, Aranda H. Revascularization of liver grafts with recipient splenic artery in liver transplantation. Transplant Proc. 1990;22:2376-7.

8. Desphande RR, Heaton ND, Rela M. Surgical anatomy of segmental liver transplantation. Br J Surg. 2002;89:1078-88.

9. Fan ST, Lo CM, Liu CL, Tso WK, Wong J. Biliary reconstruction and complications of right lobe live-donor liver transplantation. Ann Surg. 2002;236:676-83.

10. Hiatt JR, Gabbay J, Busutil RW. Surgical anatomy of the hepatic arteries in 1000 cases. Ann Surg. 1994;220:50-2.

11. Icoz G, Kilik M, Zeytunlu M, Celebri A, Ersoz G, Killi R, Nemis A, Karasu Z, Yuzer Y, Tokat Y. Biliary reconstructions and complications encountered in 50 consecutive right lobe living donor liver transplantation. Liver Transplant. 2003;9:575-80.

12. Ikegami T, Kawasaki S, Matsunami H, Hashikura Y, Nakazawa Y, Miyagawa S, Furuta $\mathrm{S}$, Iwanaka T, Maakuchi M. Should all arterial branches be reconstructed in livingrelated liver transplantation? Surgery. 1996;119:20-6.

13. Kemeny MM, Hogan JM, Goldberg DA. Continuous hepatic artery infusion with an implantable pump: problems with hepatic artery anomalies. Surgery. 1993;113:395-402.
14. Lee SG, Hwang S, Kim Kh, Ahn CS, Park KM, Lee YJ, Moon DB, Chu CW, Yang HS, Cho SH, Oh KB, Ha TY, Song KW, Yu YS, Min PC. Approach to anatomic variations of the graft portal vein in right lobe living donor liver transplantation. Transplantation. 2003; 75:s28-s32.

15. Marcos A, Ham HJ, Fisher RA, Olzinski AT, Posner MP. Surgical management of anatomical variations of the right lobe liver transplantation. Ann Surg. 2000;231:824-31.

16. Michels NA. Newer anatomy of the liver and its variant blood supply and collateral circulation. Am J Surg. 1966,112:337-46.

17. Nakamura S, Tsuzuki T. Surgical anatomy of the hepatic veins and the inferior vena cava. Surg Gynecol Obstet. 1981;152:43-50.

18. Nakamura T, Tanaka K, Kiuchi T, Kasahara M, Oike F, Ueda M, Kaihara S, Egawa H, Ozden I, Kobayashi N, Uemoto S. Anatomical variations and surgical strategies in right lobe living donor liver transplantation: lessons from 120 cases. Transplantation. 2002;73:1896-903.

19. Raia S. NerY JR, Mies S. Liver transplantation from live donors. Lancet. 1989;2:497.

20. Renz JF, Reichert PR, Emond JC. Biliary anatomy as applied to pediatric living donor and split-liver transplantation. Liver Transplant. 2000;6:801-4.

21. Settmacher U, Steinmuller TH, Schmidt SC, Heise M, Pascher A, Theruvat T, Hintze $\mathrm{R}$, Neuhaus $\mathrm{P}$. Technique of bile duct reconstruction and management of biliary complications in right lobe living donor liver transplantation. Clin Transplant. 2007; 17:37-42.

22. Testa J, Malagó M, Gamazo CV, Lindell G, Broelsh CE. Bilary anastomosis in living related liver transplantation using the right liver lobe: techniques and complications. Liver Transplant. 2000;6:710-4.

23. Testut L, Latarget A. Tratado de anatomia humana. 9a. ed. Barcelona: Salvat; 1988 .

24. Varotti G, Gondolesi GE, Wayne M, Florman SS, Schwartz ME, Miller CM, Sukru E. Anatomic variations in right liver living donors. J Am Coll Surg. 2004; 198:577-82.

Recebido em 8/8/2006 Aprovado em 8/6/2007 